\title{
Ergot Alkaloid Contents in Hybrid Rye are Reduced by Breeding
}

\author{
Thomas Miedaner ${ }^{1, * \mathbb{D}}$, Anna Kodisch ${ }^{1}$, Armin Raditschnig ${ }^{2}$ and Jakob Eifler ${ }^{3}$ \\ 1 State Plant Breeding Institute, University of Hohenheim, Fruwirthstraße 21, 70599 Stuttgart, Germany; \\ kodisch.a@uni-hohenheim.de \\ 2 Austrian Agency for Health and Food Safety (AGES), Institute for Food Safety Linz, Wieningerstrasse 8, \\ 4020 Linz, Austria; armin.raditschnig@ages.at \\ 3 KWS LOCHOW GMBH, Ferdinand-Von-Lochow-Straße 5, 29303 Bergen, Germany; Jakob.Eifler@kws.com \\ * Correspondence: miedaner@uni-hohenheim.de; Tel.: +49-711-459-22690
}

check for updates

Citation: Miedaner, T.; Kodisch, A.; Raditschnig, A.; Eifler, J. Ergot Alkaloid Contents in Hybrid Rye are Reduced by Breeding. Agriculture 2021, 11, 526. https://doi.org/ 10.3390 /agriculture 11060526

Received: 20 April 2021

Accepted: 2 June 2021

Published: 5 June 2021

Publisher's Note: MDPI stays neutral with regard to jurisdictional claims in published maps and institutional affiliations.

Copyright: (c) 2021 by the authors. Licensee MDPI, Basel, Switzerland. This article is an open access article distributed under the terms and conditions of the Creative Commons Attribution (CC BY) license (https:/ / creativecommons.org/licenses/by/ $4.0 /)$.

\begin{abstract}
Contamination by ergot caused by the phytopathogenic fungus Claviceps purpurea is a constant threat to the whole rye value chain. Ergot alkaloids (EA) produced within the fungal sclerotia are toxic for humans and animals and are subjected to strict regulations in human food. Our main objective was to analyze whether less susceptible rye cultivars with a lower content of sclerotia also contain fewer ergot alkaloids (EA). We analyzed 15 factorial single crosses in multi-environmental trials with artificial inoculation for their ergot severity, the content of twelve EAs by HPLC, and the total ergot content by ELISA. The genotypes displayed a wide range of pollen shedding from fully sterile to fully fertile, of ergot severity expressed as percentage of sclerotia relative to the harvest (0.22-11.47\%), and of EA contents when analyzed by HPLC (0.57-45.27 mg/kg. Entry-mean heritabilities were high throughout (0.87-0.98). The factorial analysis yielded a preponderance of male general combining ability (GCA) variances, the estimates for the females were smaller, although significant. EA contents measured by ELISA were, on average, seven times larger. The correlation between ergot severity and EA contents determined by HPLC was $r=0.98(p \leq 0.01)$ and only somewhat lower when analyzed by ELISA. In conclusion, less ergot prone rye genotypes also support lower EA contents.
\end{abstract}

Keywords: Claviceps purpurea; ELISA; ergot severity; HPLC; pollen; Secale cereale

\section{Introduction}

Ergot is a century-old problem in rye (Secale cereale L.) cultivation and the diseasecausing pathogen Claviceps purpurea (Fr.) Tul. has as generalist a wide host range with over 400 different grass species [1]. The fungus colonizes the unfertilized ovaries during flowering [2] and causes the plant to form large overwintering organs, the purple-black sclerotia [3]. They contain over 80 ergot alkaloids (EAs; [4]) that are dangerous to humans and animals [5]. Because the fungus competes with pollen for the stigma, any conditions where even only little pollen is available are conducive for infection. This includes cool, damp weather at flowering that further promotes fungal infection [6]. Cultivation of hybrid varieties based on cytoplasmic-male sterility (CMS) has also resulted in increased ergot incidence since the mid-1980s because the required restorer-to-fertility $(R f)$ genes provided only $30-50 \%$ pollen shedding at that time $[7,8]$. Nowadays, non-adapted restorer genes from Iranian primitive rye and Argentinean landraces are used in some hybrid varieties, which cause a considerably better restoration and, thus, a significant reduction in ergot content [9]. In the Descriptive List of Varieties of Germany, the susceptibility to ergot varies between ratings of 3-6 on the 1-9 scale (1 = fully resistant, 9 = fully susceptible; [10]).

Total ergot alkaloid (EA) contents ranging from 3 to $300 \mu \mathrm{g} / \mathrm{kg}$ have been detected in randomly collected rye samples from natural infections in Germany [11]. Because toxic EAs occur in food and feed samples consistently, there are strict European Union limits on the use of rye for human consumption with a maximum of $0.5 \mathrm{~g}$ sclerotia fragments $/ \mathrm{kg}$, and 
these limits are planned to be reduced to $0.2 \mathrm{~g} / \mathrm{kg}$ as from 1 July 2023 [12]. In this context, the six most frequent EAs (ergometrine, ergotamine, ergosine, ergocristine, ergocryptin, ergocornine; [13]) with their inine epimers are to be regulated in unprocessed rye to a maximum total content of $250 \mu \mathrm{g} / \mathrm{kg}$ from that date. Rye is used in Northern Europe mainly for bread making, feeding, and bioenergy production and for these purposes the occurrence of ergot sclerotia is harmful. Therefore, the question arises whether less susceptible rye cultivars with a lower content of sclerotia also contain fewer alkaloids. For this, we used CMS inbred lines to create 15 single crosses differing maximally in pollen shedding, tested them in multi-site field trials with artificial infection, and measured the alkaloid content using High Performance Liquid Chromatography (HPLC) analysis and a commercial Enzyme-Linked Immunosorbent Assay (ELISA).

\section{Materials and Methods}

\subsection{Field Trials and Inoculation Procedure}

Fifteen factorial single crosses were produced by crossing four female lines (SE) of the Petkus gene pool in the cytoplasmic-male sterility (CMS) inducing Pampa cytoplasma with four male lines (PE) by KWS LOCHOW GMBH, Bergen, Germany. Two of the male lines (PE2, PE4) had non-adapted $R f$ genes, one (PE3) had European $R f$ genes, all being from the Carsten gene pool, and one line (PE5) was a non-restorer from the Petkus gene pool, providing only non-pollen shedding progeny as negative control. In 2018 and 2019, the field trials were conducted at the following 6 locations: Oberer Lindenhof (OLI; $48^{\circ} 28^{\prime} 25.5^{\prime \prime} \mathrm{N} 9^{\circ} 18^{\prime} 17.9^{\prime \prime} \mathrm{E}$ ), Braunschweig (BRS; $\left.52^{\circ} 16^{\prime} 33.4^{\prime \prime} \mathrm{N} 10^{\circ} 34^{\prime} 09.3^{\prime \prime} \mathrm{E}\right)$, Wohlde

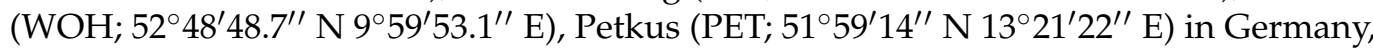
Kościelna Wieś (KOS; 51 46 $28.7^{\prime \prime} \mathrm{N} 18^{\circ} 00^{\prime} 58.0^{\prime \prime} \mathrm{E}$ ), and Zybiszów (ZYB; 51 $03^{\prime} 51.9^{\prime \prime} \mathrm{N}$ $16^{\circ} 54^{\prime} 45.4^{\prime \prime}$ E) in Poland. Data of BRS 2018 were lacking because of missing infections. The field trials were grown in a chessboard-like design with locally grown triticale $(\times$ Triticosecale Wittm.) as surrounding border plots [14] completely randomized with two replications. The size of the large-drilled plots varied between 5.0 and $6.9 \mathrm{~m}^{2}$ according to the location. Sowing was carried out in September/October with a seed density of 200 kernels $/ \mathrm{m}^{2}$, all chemical treatments (herbicide, fertilizer, fungicide, growth regulator) were applied conventionally at the different locations.

After collecting C. purpurea samples from Germany, Poland, and Austria, the laboratory of Dr. B. Rodemann (Julius Kühn-Institute, Institute for Plant Protection in Field Crops and Grassland, Braunschweig, Germany) produced the inoculum as previously described in detail by Miedaner et al. [15]. Briefly, each sample was isolated separately according to Kirchhoff [16] and autoclaved wheat-grain medium colonized by C. purpurea was used to produce conidia for inoculation. Suspending the colonized wheat in tap water and adjusting the concentration to $3 \times 10^{6}$ spores $/ \mathrm{mL}$ was done directly before inoculation. For inoculation, a mix of three country-specific inocula from Germany, Poland, and Austria were used to guarantee a wide ecological range of the inoculum, whereas the inoculation procedure was performed as described in Kodisch et al. [17].

Visual scoring of the anthers (size, dehiscence) in the field on a scale of 1-9 was done to evaluate the degree of pollen fertility as described in Geiger and Morgenstern [7] due to a highly positive correlation $(r>0.9, p \leq 0.01)$ between this anther score and pollen amount [8]. This scale varied from male-sterile (score: $1-3$ ), partially male-fertile (score: 4-6) and male-fertile (score: 7-9) plants, whereas the classes were categorized by increasing anther size. Scorings were done several times at mid-flowering of the respective plot. At dough ripening stage (BBCH 85-89; [18]), a subplot of $1 \mathrm{~m}^{2}$ from the center of the large plot was harvested by hand while avoiding secondary tillers. After drying $\left(30^{\circ} \mathrm{C}\right)$, all heads of one plot were threshed by a large single-head thresher (Pelz K 35, Saatzuchtbedarf Baumann, Waldenburg, Germany). The sclerotia and sclerotia fragments were sorted out by hand, grain and ergot samples were separately weighed and calculated as percentage of ergot sclerotia relative to the total grain sample by weight (=ergot severity). 


\subsection{Sample Preparation}

For preparing the samples for chemical analyses, grain and sclerotia were merged in sub-samples of $200 \mathrm{~g}$ according to the respective ergot severity due to a better handling. Afterwards, the sub-samples were milled (Ultra Centrifugal Mill ZM 200, $1 \mathrm{~mm}$ sieve, Retsch, Haan, Germany) and the flour was used for all analyses. Samples of OLI in 2018 and 2019 were analyzed by HPLC and ELISA.

\subsection{High Performance Liquid Chromatography (HPLC) Analysis of EAs}

HPLC analysis was performed as described in detail by Kodisch et al. [17] according to BVL L 15.01/02-5:2012-01 [19] with some minor alterations. In short, HPLC was performed for the samples from two locations (OLI18, OLI19) by the Austrian Agency for Health and Food Safety, Institute for Food Safety (AGES, Linz, Austria). Twelve EAs were quantified: ergometrine, ergometrinine, ergosine, ergosinine, ergotamine, ergotaminine, ergocornine, ergocorninine, $\alpha$-ergocryptine, $\alpha$-ergocryptinine, ergocrystine, and ergocrystinine. The EA content was determined as the sum of all individual EAs, individual EA values lower than the quantitation limit ( $\mathrm{LOQ}<0.02 \mathrm{mg} / \mathrm{kg}$ ) were taken as zero. Subsequently, the term "(total) EA content (determined) by HPLC" is related to the sum of these 12 EAs.

\subsection{Enzyme-Linked Immunosorbent Assay (ELISA) of EAs}

ELISA analysis was performed as previously described in detail by Kodisch et al. [17]. Briefly, the competitive ErgoREAD ELISA (LCTech GmbH, Obertaufkirchen, Germany) was conducted at the University of Hohenheim. After extraction and filtration, the company's internal protocol was performed and, afterwards, the extinction values were determined by a microplate reader ('Sunrise') with integrated Magellan software (Tecan Group Ltd., Männedorf, Switzerland) relative to the standard samples (0, 0.025, 0.1, 0.25, 0.5, 0.75, $\left.1 \mu \mathrm{g} \cdot \mathrm{kg}^{-1}\right)$. Higher EA concentrations were accordingly diluted to fit into this range. The EA content was calculated using the proprietary software of LCTech GmbH (Obertaufkirchen, Germany), all samples were analyzed as duplicates.

\subsection{Statistical Analyses}

For all analyses, single-plot data were used. Outliers were identified according to Bernal-Vasquez et al. [20] and handled in the following as missing values. For ergot severity and EA contents, a square-root transformation was performed because the residuals did not follow a normal distribution in any environment for biological reasons. After performing the analyses of variance (ANOVA) for each location independently, the ANOVA was computed combined across locations for each trait using the methods described in [21]. The effect of the factor 'genotype' was taken as fixed and the factors 'replication' and 'environment' as random. For all statistics, significance levels of 0.05 or 0.01 were used. Entry-mean heritability $\left(H_{G}^{2}\right)$ across all environments was calculated as the ratio of genotypic to phenotypic variance considering the number of replicates end environments [22]. The software R [23] and R-Studio (Version 3.5.1) [24] were used for all analyses including the Pearson correlation coefficient (r). In the tables and figures, the original means are reported. Multiple testing was performed by a Tukey test at $p=0.05$ as implemented in R-Studio.

\section{Results}

Fifteen single crosses consisting of four female and four male lines were tested for anther score, ergot severity, and EA contents determined by HPLC and ELISA (Table 1). 
Table 1. Means of anther score (1-9), ergot severity (\%), and ergot alkaloid (EA) contents determined by HPLC and ELISA ( $\mathrm{mg} / \mathrm{kg}$ ) across two environments for the combination of four female CMS lines and four male lines after inoculation by Claviceps purpurea.

\begin{tabular}{|c|c|c|c|c|c|c|}
\hline \multirow{2}{*}{$\begin{array}{c}\text { Female } \\
\text { Line }\end{array}$} & \multicolumn{6}{|c|}{ Male Line } \\
\hline & PE2 & PE3 & PE4 & PE5 & Mean & Sign. ${ }^{a}$ \\
\hline \multicolumn{7}{|c|}{ Anther score (1-9): } \\
\hline SE2 & 8.25 & 8.25 & 7.75 & 2.00 & 6.56 & $a$ \\
\hline SE3 & 8.00 & - & 7.50 & 3.00 & 6.17 & $a$ \\
\hline SE4 & 7.75 & 4.75 & 7.25 & 1.50 & 5.31 & $b$ \\
\hline SE5 & 7.75 & 4.00 & 7.75 & 1.75 & 5.31 & $b$ \\
\hline Mean & 7.94 & 5.67 & 7.56 & 2.06 & 5.84 & \\
\hline Sign. ${ }^{a}$ & $a$ & $b$ & $a$ & $c$ & & \\
\hline \multicolumn{7}{|c|}{ Ergot severity (\%): } \\
\hline SE2 & 0.44 & 0.57 & 0.54 & 11.47 & 3.26 & $a$ \\
\hline SE3 & 0.25 & - & 0.43 & 4.16 & 1.61 & $b$ \\
\hline SE4 & 0.22 & 1.63 & 0.37 & 5.12 & 1.84 & $b$ \\
\hline SE5 & 0.31 & 3.09 & 0.39 & 6.76 & 2.64 & $a b$ \\
\hline Mean & 0.31 & 1.76 & 0.43 & 6.88 & 2.34 & \\
\hline Sign. ${ }^{a}$ & $a$ & $b$ & $a$ & $c$ & & \\
\hline \multicolumn{7}{|c|}{ EAs HPLC (mg/kg): } \\
\hline SE2 & 5.25 & 1.51 & 1.02 & 45.27 & 13.26 & $a$ \\
\hline SE3 & 0.57 & - & 1.72 & 11.28 & 4.52 & $c$ \\
\hline SE4 & 0.92 & 6.48 & 1.54 & 17.27 & 6.55 & $b$ \\
\hline SE5 & 1.91 & 9.99 & 2.25 & 16.35 & 7.63 & $b$ \\
\hline Mean & 2.16 & 5.99 & 1.63 & 22.54 & 7.99 & \\
\hline Sign. ${ }^{a}$ & $a$ & $b$ & $a$ & c & & \\
\hline \multicolumn{7}{|c|}{ EAs ELISA (mg/kg): } \\
\hline SE2 & 32.64 & 18.30 & 28.40 & 75.82 & 38.79 & $a$ \\
\hline SE3 & 20.94 & - & 43.67 & 133.09 & 65.90 & $b$ \\
\hline SE4 & 22.13 & 51.29 & 27.28 & 126.99 & 56.92 & $a b$ \\
\hline SE5 & 55.85 & 112.99 & 27.06 & 88.48 & 71.10 & $b$ \\
\hline Mean & 32.89 & 60.86 & 31.60 & 106.10 & 58.18 & \\
\hline Sign. $^{a}$ & $a$ & $a$ & $a$ & $b$ & & \\
\hline
\end{tabular}

The crosses displayed the whole range of pollen shedding from full male sterility (AS 1.50) to full male fertility (AS 8.25) by the variation of the males possessing none (PE5), only European (PE3), and additionally non-adapted $R f$ genes (PE2, PE4). Accordingly, they differed significantly $(p \leq 0.05)$ in their mean performance with anther scores ranging from 2.06 to 7.94 on the 1-9 scale. Also, the female lines showed a significant $(p \leq 0.05)$, although much smaller difference in AS ranging from 5.31 to 6.56. Especially, SE2 could be fully restored by the European $R f$ line PE3, while this male led only to low anther scores with SE4 and SE5, illustrating a specific combining ability. Ergot severities ranged widely from $0.22 \%$ to $11.47 \%$ across 11 environments. Highly positive and significant correlations were observed for ergot severities $(r=0.97 ; p \leq 0.001$, Figure $1 \mathrm{a}$ and anther scores $(r=0.98 ; p \leq 0.001$, Figure $1 \mathrm{~b})$ when comparing all 11 environments and the two test environments (OLI18, OLI19) used for alkaloid analyses illustrating the representativeness of the test environments. 


\section{a. Ergot severity (\%)}

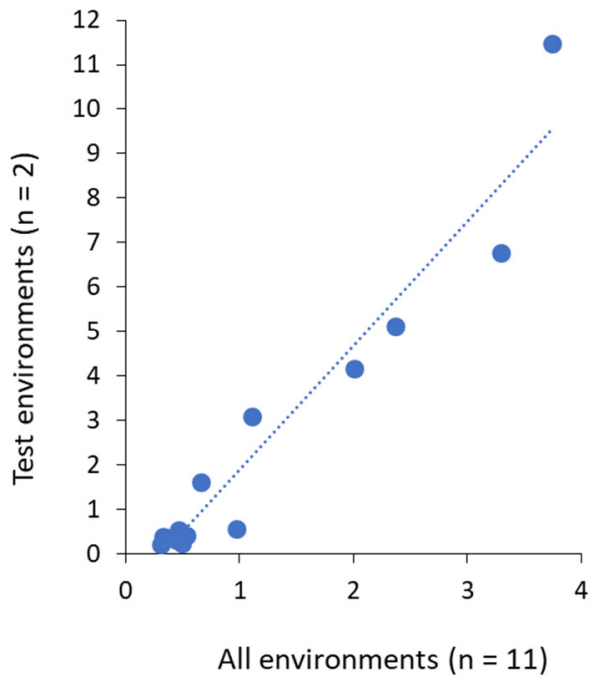

b. Anther score (1-9)

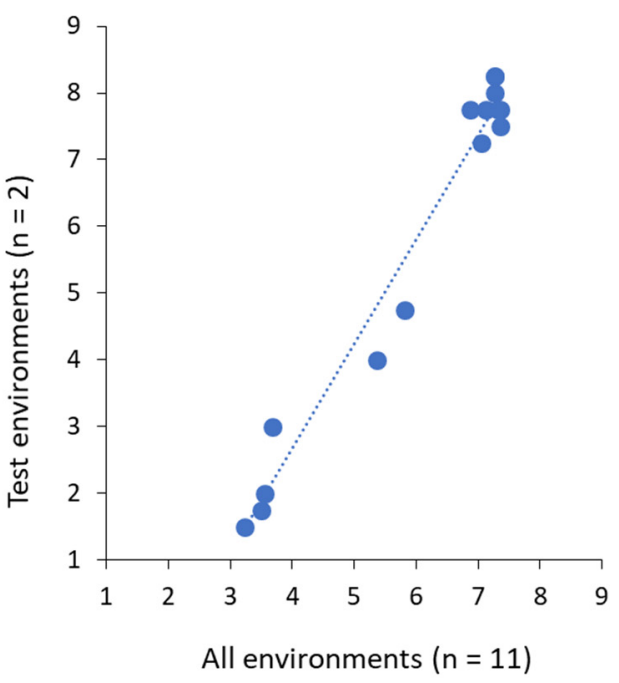

Figure 1. Association across all environments vs. test environments for 15 single crosses after inoculation with C. purpurea for (a): ergot severity (\%) and (b): anther score (1-9).

A clear negative association between ergot severity and anther scores was found for the two test environments $(r=-0.87, p \leq 0.01)$. The same narrow association between anther score and ergot severity was also found across all 11 environments $(r=-0.91, p \leq 0.01)$. The factorial crosses also differed strongly for their EA contents ranging from 0.57 to $45.27 \mathrm{mg} / \mathrm{kg}$ when analyzed by HPLC. The combination SE2 $\times$ PE5 had an unusually high EA content. The EA contents measured by ELISA were, on average, seven times higher than analyzed with HPLC. Nevertheless, the correlation between both analytical methods was significant $(r=0.53, p \leq 0.05)$. When the combination SE2 $\times$ PE5 was omitted from this analysis, the coefficient of correlation between both methods was raised to $r=0.87$ $(p \leq 0.01)$. The correlations between ergot severity and EA contents determined by HPLC and ELISA were $r=0.98(p \leq 0.01$, Figure 2$)$ and $r=0.63(p \leq 0.05$, without SE2 $\times$ PE5: $r=0.84, p \leq 0.01)$, respectively.

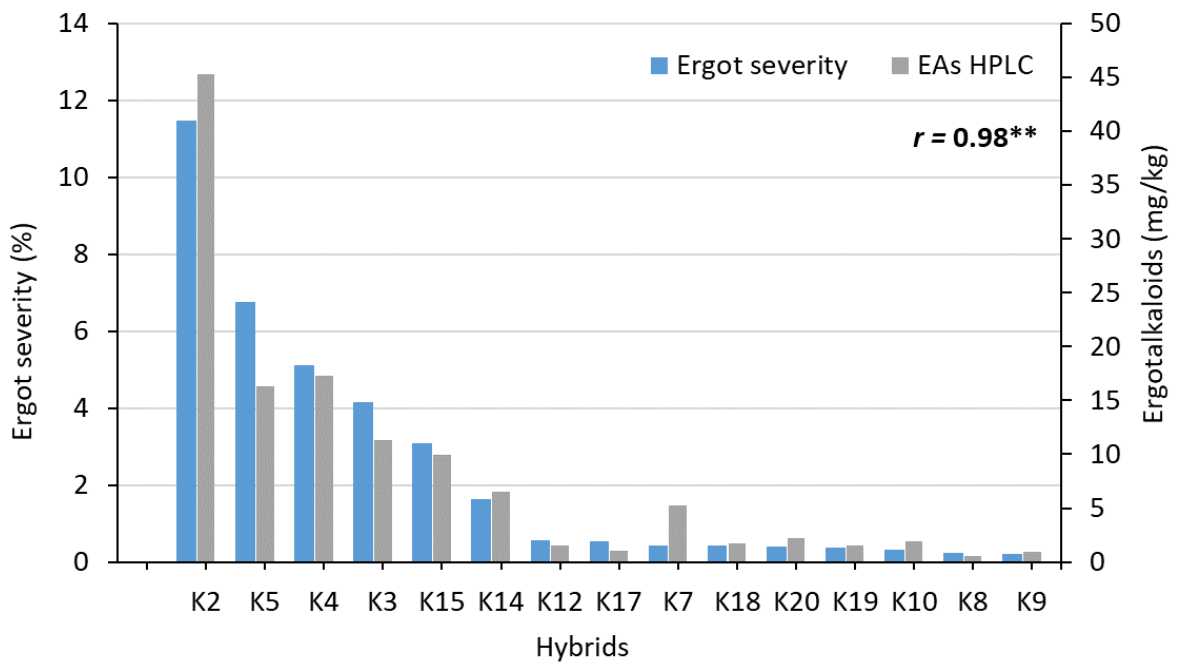

Figure 2. Association between ergot severity (\%) and ergot alkaloids (EAs, $\mathrm{mg} / \mathrm{kg}$ ) determined by HPLC across 2 environments (OLI18, OLI19) for 15 single crosses after inoculation with C. purpurea $\left(r=\right.$ coefficient of correlation, ${ }^{* *}$ : significant at $\left.p<0.01\right)$. 
The analyses of variance showed very high genotypic entry-mean heritabilities ranging from 0.80 to 0.98 (Table 2).

Table 2. Estimates of variance components for general (GCA) and specific combining ability (SCA) and genotypic entrymean heritability $\left(H_{G}^{2}\right)$ of four female CMS lines and four male restorer lines for ergot severity, anther score (AS), and ergot alkaloid (EA) contents analyzed by HPLC and ELISA across all environments $(n=11)$ and the test environments $(n=2)$.

\begin{tabular}{|c|c|c|c|c|c|c|c|c|c|c|c|c|}
\hline & \multicolumn{4}{|c|}{ All Environments $(n=11)$} & \multicolumn{8}{|c|}{ Test Environments $(n=2)$} \\
\hline Parameter & \multicolumn{2}{|c|}{ Ergot Severity $^{a}$} & \multicolumn{2}{|c|}{ Anther Score } & \multicolumn{2}{|c|}{ Ergot Severity $^{a}$} & \multicolumn{2}{|c|}{ Anther Score } & \multicolumn{2}{|c|}{ EA Content HPLC $^{\text {a }}$} & \multicolumn{2}{|c|}{ EA Content ELISA $^{\text {a }}$} \\
\hline GCA male (M) & 13.07 & $* * *$ & 271.98 & $* * *$ & 13.39 & $* * *$ & 115.5 & $* * *$ & 1429 & $* * *$ & 17612 & $* * *$ \\
\hline GCA female $(\mathrm{F})$ & 0.37 & $* *$ & 5.64 & $* * *$ & 0.38 & $* * *$ & 6.08 & ** & 182 & $* * *$ & 3849 & * \\
\hline SCA & 0.25 & $* *$ & 4.04 & $* * *$ & 0.57 & $* * *$ & 3.69 & $* *$ & 242 & $* * *$ & 2845 & $*$ \\
\hline $\mathrm{M} \times$ environment $(\mathrm{E})$ & 1.32 & $* * *$ & 17.44 & $* * *$ & 0.68 & $* * *$ & 0.06 & & 831 & $* * *$ & 3586 & * \\
\hline $\mathrm{F} \times \mathrm{E}$ & 0.17 & $* *$ & 1.13 & & 0.16 & $*$ & 0.58 & & 158 & $* * *$ & 3243 & \\
\hline $\mathrm{F} \times \mathrm{M} \times \mathrm{E}$ & 0.14 & $* *$ & 1.26 & * & 0.15 & * & 1.25 & & 190 & $* * *$ & 3032 & * \\
\hline Error & 0.08 & & 0.83 & & 0.05 & & 1.01 & & 5 & & 1159 & \\
\hline$H_{G}^{2}$ & 0.87 & & 0.89 & & 0.95 & & 0.88 & & 0.98 & & 0.8 & \\
\hline
\end{tabular}

$*{ }^{* *}, * *$ Significant at $p=0.05,0.01,0.001$, respectively. ${ }^{\text {a }}$ Data have been square-root transformed.

The estimates for ergot severity and anther scores across the test environments were of the same magnitude of those calculated across all environments. The variances of the male lines were of highest importance for all traits. The shares of the female lines and that of the female $\times$ male interaction (SCA, specific combining ability) were of equal size. The interactions with environments were significant for ergot severities and EA content measured by HPLC but of lesser importance for the other traits. Calculated across the genetic variance, the share of the male parent was $93 \%$ and $92 \%$ for ergot severity and anther score and $77 \%$ and $73 \%$ for EA contents measured by HPLC and ELISA, respectively. The female and SCA effects had also clearly an impact on alkaloid contents.

The fifteen single crosses did not show large deviations in their amount (\%) of the individual EA profile relative to the total EA content (Supplementary Table S2). The most important individual EA was ergocristin, followed by alpha-ergocryptin and ergotamine. The amount of the -inine epimers were in all cases lower than the respective -in form.

\section{Discussion}

Ergot alkaloids are clearly an important concern in the total rye value chain. Although high concentrations are rarely found in food samples, the stricter EU regulations expected in 2023 [12] and general concerns of consumers on food security cast a poor image upon the acceptance of rye. Even worse, home-grown rye is not controlled and can be suspected to have even higher alkaloid concentrations despite the high sensitivity of some livestock [13]. Because no fungicides against ergot are registered on the EU market [25,26], it is of utmost importance to reduce ergot sclerotia in the rye harvest by breeding. It was shown previously that cultivars with a high pollen shedding lead always to a lower ergot contamination $[27,28]$, thus confirming the tight correlations between anther score and ergot severity found here among 15 single crosses.

In our study, ergocristin and alpha-ergocryptin were the main EAs. In the literature, the abundance of the single EAs differed strongly with the experiments [29-31], therefore, it was shown again that shifting of the EA profile seems to happen regularly. Only the fact seems to be consistent that the amounts of the -inine epimers are lower than the respective -in forms, which was also the case here. These -inine epimers are probably biologically inactive but can also be contributing to the toxicity due to epimerization conversions [13].

In recent studies, only a moderate correlation between ergot severity and EA content was found in rye [11]. Additionally, a large screening approach of 372 winter rye samples across three cultivars, three isolates, eleven locations in three countries, and two years resulted in a similar moderate, positive covariation between ergot severity and EA content determined by HPLC ( $r=0.53, p<0.01$, [17]). Obviously, EA contents are highly affected by the interactions with isolates, locations, and years. However, when we concentrate on genotypic differences such as in this study, correlations between ergot severity and 
EA content become obviously much closer. An explanation could be the low number of environments in this study. However, the two locations used for the chemical analysis differed strongly for ergot severity as well as for anther score while both traits correlated nearly perfectly with the full number of environments. So, the data are representative and could be probably extrapolated, but of course, it has to be verified in future datasets. This also confirms the findings of Tittlemier et al. [32] where a strong linear relationship of ergot sclerotia and EA concentration could be detected in wheat.

Ergot severities at the two test environments were considerably higher than among the 11 environments. This was probably caused by the fact that the test location OLI has a very high amount of yearly precipitation [33] and the year 2018 was extremely dry in other locations, which is well known to hinder ergot infection [6]. This shows once again the necessity of having suitable locations for ergot testing [34]. Another important point for correlation analyses is, that we had here a maximum range of ergot severity and EA contents among the 15 single crosses from $0.22 \%$ to $11.47 \%$ and 0.57 to $45.27 \mathrm{mg} / \mathrm{kg}$, respectively. This was not given in the earlier calibration study where we tested only three genotypes with only a small difference regarding their ergot reaction [17]. In this earlier study, the main differences among EA contents came from isolate and environmental factors. Screening approaches that are fast, cheap, and easy to handle were found to be not yet convincing because of a poor relationship between ELISA and HPLC results in recent calibration studies [28,35]. The correlation of ELISA and HPLC found in this study was moderate, which could also be caused by the higher range for ergot reaction of the genotypes here.

The high preponderance of the male GCA variance for ergot severity illustrates that it is promising to reduce ergot susceptibility in hybrid rye by breeding for high pollen shedding, e.g., by introgressing non-adapted $R f$ genes [9] or by using alternative CMS cytoplasms that are easier to restore [36]. However, when a high pollen shedding is integrated in all rye hybrid breeding programs, the only way to make further achievements in reducing ergot towards the low percentages known from wheat is an additional resistance of the female parent for which first indications have been shown in this study and elsewhere $[15,37]$. This might be also of great importance for reducing EA contents in future breeding programs because the female lines contributed to the EA contents $10 \%$ to $16 \%$ of the total genetic variance compared to only $2.6 \%$ for ergot severity.

\section{Conclusions}

We could demonstrate that hybrid cultivars with a low proportion of sclerotia in the harvest also contain less EA content, which is auspicious for farmer, milling, and breeding companies as well as consumers. In future, this tight correlation between ergot severity and EA content should be substantiated by a larger number of hybrids that show a distinct reaction to ergot, and additionally maternal effects should be further exploited in breeding programs with an increased effort to reduce EA content to meet the future limits.

Supplementary Materials: The following are available online at https: / www.mdpi.com/article/ 10.3390/agriculture11060526/s1, Table S1: Means of anther score (1-9). ergot severity (\%). and ergot alkaloid contents $(\mathrm{mg} / \mathrm{kg})$ measured by HPLC and ELISA of 15 single-cross hybrids across all environments and the test environments after inoculation by Claviceps purpurea, Table S2: Ergot severity (\%) and individual and total ergot alkaloid contents $(\mathrm{mg} / \mathrm{kg})$ measured by HPLC of 15 hybrids across two environments.

Author Contributions: Conceptualization, T.M.; Methodology, T.M.; Software, A.K.; Validation, A.K. and T.M.; Formal Analysis, A.K. and J.E.; Investigation, A.K., J.E., and A.R.; Resources, A.K., J.E., and T.M.; Data Curation, A.K. and T.M.; Writing-Original Draft Preparation, T.M.; Writing-Review and Editing, T.M. and A.K.; Visualization, A.K.; Supervision, T.M.; Project Administration, T.M.; Funding Acquisition, T.M. All authors have read and agreed to the published version of the manuscript.

Funding: This research was funded by Federal Ministry for Economic Affairs and Energy via the German Federation of Industrial Research Associations (AiF) in the frame of CORNET (Grant No. 
188EN/1) and the plant breeding companies KWS LOCHOW GMBH and HYBRO Saatzucht GmbH \& Co. KG, Additional support was provided by the German Society for the Promotion of Plant Innovation (GFPi, Bonn).

Institutional Review Board Statement: Not applicable.

Data Availability Statement: Data is contained within the article or supplementary material.

Acknowledgments: The authors want to thank B. Rodemann, Julius Kuehn Institute, Braunschweig, Germany, A. Tratwal and J. Danielewicz, Institute of Plant Protection-National Research Institute, Poznań, Poland, for providing field data, and J. Jacobi (GFPi) for administrative help.

Conflicts of Interest: The authors declare no conflict of interest. The funders had no role in the design of the study; in the collection, analyses, or interpretation of data; in the writing of the manuscript, or in the decision to publish the results.

\section{References}

1. Wegulo, S.N.; Carlson, M.P. Ergot of Small Grain Cereals and Grasses and its Health Effects on Humans and Livestock. 2011. University of Nebraska, Extension, EC1880. Available online: http://ianrpubs.unl.edu/live/ec1880/build/ec1880.pdf (accessed on 9 March 2021).

2. Pažoutová, S. The evolutionary strategy of Claviceps. In Clavicipitalean Fungi: Evolutionary Biology, Chemistry, Biocontrol and Cultural Impacts; White, F., Bacon, C.W., Hywel-Jones, N.L., Eds.; Marcel Dekker: New York, NY, USA, 2002; pp. 329-354.

3. Schumann, G.L.; Uppala, S. Ergot of rye. The Plant Health Instructor. 2000. Updated 2017. Available online: https://www.apsnet. org/edcenter/disandpath/fungalasco/pdlessons/Pages/Ergot.aspx (accessed on 10 February 2021).

4. Schiff, P.L. Ergot and its alkaloids. Am. J. Pharm. Educ. 2006, 70, 98. [CrossRef]

5. Hulvová, H.; Galuszka, P.; Frébortová, J.; Frébort, I. Parasitic fungus Claviceps as a source for biotechnological production of ergot alkaloids. Biotechnol. Adv. 2013, 31, 79-89. [CrossRef] [PubMed]

6. Miedaner, T.; Geiger, H.H. Biology, genetics, and management of ergot (Claviceps spp.) in rye, sorghum, and pearl millet. Toxins 2015, 7, 659-678. [CrossRef] [PubMed]

7. Geiger, H.H.; Morgenstern, K. Applied genetic studies oncytoplasmic pollen sterility in winter rye (Angewandt-genetische Studien zur cytoplasmatischen Pollensterilität bei Winterroggen). Theor. Appl. Genet. 1975, 46, 269-276. (In German) [CrossRef] [PubMed]

8. Geiger, H.H.; Yuan, Y.; Miedaner, T.; Wilde, P. Environmental sensitivity of cytoplasmic genic male sterility (CMS) in Secale cereale L. In Genetic Mechanisms for Hybrid Breeding (Advances in Plant Breeding, 18); Kück, U., Wricke, G., Eds.; Paul Parey Scientific Publishers: Berlin, Germany, 1995; pp. 7-17.

9. Miedaner, T.; Wilde, P.; Wortmann, H. Combining ability of non-adapted sources for male-fertility restoration in Pampa CMS of hybrid rye. Plant Breed. 2005, 124, 39-43. [CrossRef]

10. BSL (Beschreibende Sortenliste) Cereals, Maize, Oil and Fiber Plants, Legumes, Beets, Cover Crops [Getreide, Mais, Öl- und Faserpflanzen, Leguminosen, Rüben, Zwischenfrüchte] (In German). Hannover. 2020. Available online: https://www. bundessortenamt.de/bsa/sorten/beschreibende-sortenlisten/download-bsl-im-pdf-format (accessed on 28 March 2021).

11. Schwake-Anduschus, C.; Lorenz, N.; Lahrssen-Wiederholt, M.; Lauch, A.; Dänicke, S. German monitoring 2012-2014: Ergot of Claviceps purpurea and ergot alkaloids (EA) in feeding stuffs and their toxicological relevance for animal feeding. J. Consum. Prot. Food Saf. 2020, 15, 321-329. [CrossRef]

12. Raditsching, A.; Austrian Agency for Health and Food Safety (AGES), Institute for Food Safety, Linz, Austria. Personal communication, 2020.

13. European Food Safety Authority (EFSA). Scientific Opinion on Ergot Alkaloids in Food and Feed. EFSA Panel on Contaminants in the Food Chain (CONTAM). 2012. EFSA 10: 2798. Available online: http:/ / onlinelibrary.wiley.com/doi/10.2903/j.efsa.2012.2 798/pdf (accessed on 12 March 2021).

14. Miedaner, T.; Mirdita, V.; Rodemann, B.; Drobeck, T.; Rentel, D. Genetic variation of winter rye cultivars for their ergot (Claviceps purpurea) reaction tested in a field design with minimized interplot interference. Plant Breed. 2010, 129, 58-62. [CrossRef]

15. Miedaner, T.; Dänicke, S.; Schmiedchen, B.; Wilde, P.; Wortmann, H.; Dhillon, B.S.; Mirdita, V. Genetic variation for ergot (Claviceps purpurea) resistance and alkaloid concentrations in cytoplasmic-male sterile winter rye under pollen isolation. Euphytica 2010, 173, 299-306. [CrossRef]

16. Kirchhoff, H. Contributions to the biology and physiology of the ergot fungus [Beiträge zur Biologie und Physiologie des Mutterkornpilzes] (In German). Centralbl. Bakteriol. Parasitenk. Abt. II 1929, 77, 310-369.

17. Kodisch, A.; Oberforster, M.; Raditschnig, A.; Rodemann, B.; Tratwal, A.; Danielewicz, J.; Korbas, M.; Schmiedchen, B.; Eifler, J.; Gordillo, A.; et al. Covariation of ergot severity and alkaloid content measured by HPLC and one ELISA Method in inoculated winter rye across three isolates and three European countries. Toxins 2020, 12, 676. [CrossRef] [PubMed]

18. Meier, U. Growth Stages of Mono- and Dicotyledonous Plants. BBCH Monograph. 2001. Available online: https://www.juliuskuehn.de/media/Veroeffentlichungen/bbch\%20epaper\%20en/page.pdf (accessed on 4 March 2021). 
19. BVL L 15.01/02-5:2012-01. Investigation of food-determination of ergot alkaloids in rye and wheat-HPLC method with purification on a basic aluminum oxide solid phase [Untersuchung von Lebensmitteln-Bestimmung von Ergotalkaloiden in Roggen und Weizen-HPLC-Verfahren mit Reinigung an einer basischen Aluminiumoxid-Festphase]. 2012. Available online: https:/ / www.beuth.de/de/technische-regel/bvl-1-15-01-02-5/150736503 (accessed on 4 June 2021). (In German)

20. Bernal-Vasquez, A.M.; Utz, H.F.; Piepho, H.P. Outlier detection methods for generalized latt ices: A case study on the transition from ANOVA to REML. Theor. Appl. Genet. 2016, 129, 787-804. [CrossRef] [PubMed]

21. Cochran, W.G.; Cox, G.M. Experimental Designs; Wiley: New York, NY, USA, 1957; ISBN 978-0-471-54567-5.

22. Fehr, W.R. Principles of Cultivar Development, Theory and Technique; Macmillan: New York, NY, USA, 1987; Volume 1, ISBN 0029499208

23. R Core Team. R: A Language and Environment for Statistical Computing; R Foundation for Statistical Computing: Vienna, Austria, 2018; ISBN 3-900051-07-0.

24. RStudio Team. RStudio: Integrated Development for R; RStudio, Inc.: Boston, MA, USA, 2016; Available online: https://www. rstudio.com/ (accessed on 4 March 2021).

25. Alderman, S. Ergot: Biology and Control. 2006. Available online: https://www.ars.usda.gov/SP2UserFiles/person/81 /ErgotDVDtranscript.pdf (accessed on 26 March 2021).

26. Engelke, T. Approaches for an Integrated Control of Ergot (Claviceps purpurea [Fr.] Tul.) in Rye [Ansätze für eine integrierte Bekämpfung des Mutterkorns (Claviceps purpurea [Fr.] Tul.) im Roggen]. Ph.D. Thesis, University of Göttingen, Göttingen, Germany, 2002. (In German)

27. Miedaner, T.; Wilde, P. Selection strategies for disease-resistant hybrid rye. In Advances in Breeding Techniques for Cereals; Ordon, F., Friedt, W., Eds.; Burleigh Dodds Science Publishing: Cambridge, UK, 2019; pp. 223-246, ISBN 978-1786762443.

28. Kodisch, A.; Wilde, P.; Schmiedchen, B.; Fromme, F.J.; Rodemann, B.; Tratwal, A.; Oberforster, M.; Wieser, F.; Schiemann, A.; Jørgensen, L.N.; et al. Ergot infection in winter rye hybrids shows differential contribution of male and female genotypes and environment. Eupyhtica 2020, 216, 65. [CrossRef]

29. Blaney, B.J.; Molloy, J.B.; Brock, I.J. Alkaloids in Australian rye ergot (Claviceps purpurea) sclerotia: Implications for food and stockfeed regulations. Anim. Prod. Sci. 2009, 49, 975-982. [CrossRef]

30. Kniel, B.; Meißner, M.; Koehler, P.; Schwake-Anduschus, C. Studies on the applicability of HPLC-FLD and HPLC-MS/MS for the determination of ergot alkaloids in rye-containing breads. J. Consum. Prot. Food Saf. 2018, 13, 69-78. [CrossRef]

31. Müller, C.; Kemmlein, S.; Klaffke, H.; Krauthaus, W.; Preiß-Weigert, A.; Wittkowski, R. A basic tool for risk assessment: A new method for the analysis of ergot alkaloids in rye and selected rye products. Mol. Nutr. Food Res. 2009, 53, 500-550. [CrossRef] [PubMed]

32. Tittlemier, S.A.; Drul, D.; Roscoe, M.; McKendry, T. Occurrence of ergot and ergot alkaloids in western Canadian wheat and other cereals. J. Agric. Food Chem. 2015, 63, 6644-6650. [CrossRef] [PubMed]

33. Agrarmeteorologie Baden-Württemberg. Available online: https:/ /www.wetter-bw.de (accessed on 10 March 2021).

34. Dhillon, B.S.; Mirdita, V.; Miedaner, T. Preliminary evaluation of locations for conducting selection for resistance to ergot (Claviceps purpurea) in rye. Indian J. Plant Genet. Resour. 2010, 23, 265-268.

35. Veršilovskis, A.; Fauw, D.P.K.H.P.; Smits, N.; Mulder, P.P.J.; Mol, H.; de Nijs, M. Screening of Ergot Alkaloids by ELISA Test. Kits available on the Market. EURL Mycotoxins and Plant Toxins; Wageningen Food Safety Research, Part of Wageningen University \& Research: Wageningen, The Netherlands, 2019; EURL-MP-report_001; Available online: https:/ /www.wur.nl/en/show / EURLMP-report_001-Screening-of-ergot-alkaloids-using-ELISA-kits.htm (accessed on 12 March 2021).

36. Vendelbo, N.; Mahmood, K.; Sarup, P.; Kristensen, P.; Orabi, J.; Jahoor, A. Genetic architecture of male fertility restoration in a hybrid breeding system of rye (Secale cereale L.). Res. Sq. 2021. reprinted in Res. Sq. 2021. Available online: https: / / assets.researchsquare.com/files/rs-275908/v1_stamped.pdf (accessed on 31 March 2021). [CrossRef]

37. Kodisch, A.; Schmiedchen, B.; Eifler, J.; Gordillo, A.; Siekmann, D.; Fromme, F.J.; Oberforster, M.; Miedaner, T. Maternal differences for the reaction to ergot in unfertilized hybrid rye (Secale cereale). Eur. J. Plant. Pathol. 2021, submitted. 